\title{
Maistrovo stoletje: od vojaka do mita
}

Peter Simonič

Rudolf Maister je bil prvi general v slovenski zgodovini, ki je pomembno vplival na oblikovanje slovenske države. Njegovemu življenju in delu je bilo posvečenih mnogo knjig in člankov, večinoma napisanih v slovenščini in s strani mariborskih intelektualcev (Švajncer 1988; Hartman 1998; Revija za zgodovino in narodopisje 2011; itd.). Avtorji so se večinoma ukvarjali z njegovimi osebnimi značilnostmi in njegovim vplivom v lokalnem in nacionalnem prostoru. Pomembnejši zgodovinarji in etnologi iz Ljubljane so bili do dogodkov v vzhodni Sloveniji pred in po prvi svetovni vojni večinoma ravnodušni (prim. Mal 1928; Čepič 1991; Pleterski 1998; Jezernik 2008).

Mitologije Rudolfa Maistra ne moremo razložiti in razumeti, če opazujemo samo njegovo trenutno ikonografijo. Članek zato 
obravnava družbene predpogoje, ki so omogočili in osmislili Maistrove vojaške operacije, glavna Maistrova dejanja, neposredne odzive na prevrat in oblikovanje označevalcev njegovega spomina v dvajsetem stoletju: ti dejavniki skupaj določajo polje mitološke semiotike. Najprej predstavim širše zgodovinske okoliščine, pri čemer upoštevam spoznanja slovenskih, avstrijskih, britanskih in ameriških raziskovalcev. Čeprav je slovensko zgodovinopisje dvajsetega stoletja predvsem preučevalo emancipacijo »matičnega naroda « in (teleološko) sledilo izgradnji slovenske države, je bila populacija na tem ozemlju skozi dvajseto stoletje ves čas sestavni del različnih večetničnih ali federativnih držav: Habsburške monarhije in Avstro-Ogrske (od srednjega veka do 1918), kraljevine Srbov, Hrvatov in Slovencev/Jugoslavije (od leta 1918 do 1941) in republike Jugoslavije (od leta 1945 do 1991) ter nazadnje del Evropske unije od 2003 (glej Case 2013). V dvajsetem stoletju so se spremenile tudi prevladujoče ideologije obravnavanega prostora, ki segajo od katoliškega monarhizma in liberalizma do komunizma. Dojemanje Maistra in drugih herojev je vedno ustrezalo političnemu in ekonomskemu okviru (prim. Jezernik 2013). Maistra spremljam kot osebnost iz devetnajstega stoletja in prve svetovne vojne, ki je nato $\mathrm{v}$ dvajsetem stoletju pridobivala različne interpretacije in konotacije. V razpravi uporabljam predvsem sekundarne vire, ki sem jih za tukajšnji namen reorganiziral in kritično ovrednotil.

Na delovanje in dojemanje Rudolfa Maistra kot javne in zgodovinske osebnosti je po mojem mnenju izvorno in skozi dvajseto stoletje vplivala trojna bipolarnost - pogled iz Ljubljane in iz Maribora, etničnost $\mathrm{v}$ odnosu do multinacionalizma ter razredna delitev.

\section{UMESTITEV ŠTAJERSKE}

Dežela Štajerska je bila od konca srednjega veka del Habsburške monarhije, pred tem pa je pripadala Karantaniji in Karantanski krajini ter pozneje ogrskim in češkim kraljem. Frederik III., vojvoda Štajerske, Koroške in Kranjske, ki je živel na različnih lokacijah, vključno z Gradcem, je postal prvi sveti rimski cesar iz Habsburške družine. Bil je tudi zadnji, ki so ga okronali v Rimu (1452). Eden od njegovih daljnih dedičev, Karl II., je ustoličil Gradec kot upravno, versko, izobraževalno in gospodarsko središče. Šele leta 1619 je Dunaj postal prestolnica Habsburškega cesarstva (Karner 2005: 23).

Ta dejstva so pomembna za regionalno politično mitologijo in uveljavljanje »dednih pravic« na Štajerskem. Ne glede na nekatere 
resne zgodovinske ideološke in ekonomske spopade (osmanski vdori, protestantizem, protireformacija, absolutizem ipd.), ki so zagotovo spremenili politično pokrajino vojvodine, pa se njene meje niso izpraševale do sredine devetnajstega stoletja, ko sta liberalizem in nacionalizem začela spodkopavati evropske imperialne tradicije. Štajerska $s$ Kranjsko in Koroško je bila od šestnajstega stoletja habsburška dedna dežela, ustanovljena za zaščito imperialnih (fevdalnih in verskih) interesov, ne pa interesov prebivalcev (Taylor 1948: 9). »Revščina srednje Evrope je bila posledica velikih posesti, ki so preživele pod habsburško zaščito, in pozneje zgoščenosti industrije $\mathrm{v}$ nemških rokah. Obeh bi se mogli odrešiti z osvoboditvijo izpod habsburške vladavine « (Taylor 1948: 256-57). Toda najpomembnejši štajerski veleposestniki - družina Attems - niso bili pomembni le $\mathrm{v}$ gospodarskem, ampak tudi političnem oziru. Grof Edmund Attems je bil recimo deželni glavar Štajerske od leta 1897 do 1918 (Karner 2005: 40).

Od leta 1870 do 1890 je kmečko prebivalstvo Avstrije trpelo za posledicami peronospore na eni strani in zaradi polovičnega padca cen pšenice na drugi (Baš 1988: 36). Morali so se preseljevati v mesta ali tujino (ZDA, Argentino, Avstralijo, Francijo ipd.). Tudi po okrevanju avstro-ogrskega gospodarstva leta 1900 sta bila na Kranjskem ekonomska depresija in izseljevanje statistično največja (Pleterski 1998: 67). V popisu leta 1910 je bilo na Zgornjem Štajerskem registriranih skoraj milijon etničnih Nemcev, na Spodnjem Štajerskem pa več kot 400.000 večinskih, a podeželskih Slovencev. Maribor (nemško Marburg [an den Drau]) je bil nemško (administrativno) središče, obdano z etničnimi Slovenci (Ude 1988; Hartman 1998: 36; Karner 2005; Moll 2007: 210). Isti popis je pokazal, da je v Mariboru leta 1910 živelo 3500 Slovencev in 22.000 Nemcev (Baš 1988: 31; Hartman 1998: 37). Nemci na Spodnjem Štajerskem, približno deset odstotkov prebivalstva, so nadzirali okoli osemdeset do devetdeset odstotkov vsega premoženja (Moll 2007: 210), kar je v devetnajstem stoletju pomenilo, da so kulturne in jezikovne razlike štajerske družbe odsevale tudi družbeno-ekonomsko ali razredno pripadnost nosilcev.

Slovenska ljudska stranka (SLS, ustanovljena leta 1892 v Ljubljani) je predstavljala mešanico katoliškega in etničnega programa. Njeni pomembnejši zastopniki so bili Karel Klun, Fran Povše, Ivan Šušteršič, Janez Evangelist Krek, Franc Kovačič, Anton Korošec, Karel Verstovšek in drugi. Stranka je bila politično in ekonomsko zavezana katoliškim podeželskim skupnostim. Po pojavu Bismarckove Nemčije in Berlinskem kongresu (1878) je bila SLS zadolžena za preoblikovanje etničnosti v narodnost (glej Gellner 1983). Martin Moll (2007a: 210-11) je slovenski politični prevzem na Kranjskem v 
1880-ih letih opisal kot » pomemben premik nemško-slovanske fronte proti severu «.

SLS je tudi na Štajerskem zastopala slovensko stran političnega boja do prve in nato druge svetovne vojne. Teološki in jezikovni program škofa Antona Martina Slomška je od leta 1859 gotovo prispeval $\mathrm{k}$ uveljavitvi te struje. Njegova teološka šola v Mariboru je izobrazila več uglednih slovenskih politikov, med njimi tudi dr. Antona Korošca (Bister 1991; Hauc 1991). Vodstvo SLS je bilo na Kranjskem majhno, še manjše na Štajerskem in skoraj nepomembno na Koroškem. Temu ustrezni so bili časovni zamiki pri implementaciji njihovih politik v treh deželah. Nekateri štajerski člani stranke SLS so bili poslanci deželnega zbora v Gradcu ali zveznega parlamenta na Dunaju.

Socialni demokrati so bili druga najmočnejša politična skupina na Štajerskem. Imeli so majhno, a naraščajoče volilno telo: industrijske delavce. Delovali so v skladu z nemško promarksistično socialdemokratsko stranko (SDP, ustanovljena leta 1875), ki je imela regionalno pisarno tudi v Gradcu (Baš 1988: 29). Stranka se je osredotočala na razred, namesto na narod; vprašanje jezika je bilo sekundarno (glej Scott 2008: 38, 43; Filipič 1991).

Prizadevanja SLS za slovensko nacionalno priznanje pred in med prvo svetovno vojno niso podvomila v vladavino habsburške dinastije oziroma Dunaja (Hartman 1998: 29, 31; Ude 1988: 85-90; Moll 2007, navedeno na Wörsdörferju 2007). Toda z vojaškim absolutizmom, razpustitvijo parlamenta in aretacijami (Pleterski 1988: 297; Ude 1988: 85-6; Pančur 2005: 124), sploh pa po avstro-ogrskih vojaških porazih na italijanski fronti (Hartman 1998: 37), je nacionalna SLS pospešeno začela iskati partnerje med drugimi južnimi Slovani $\mathrm{v}$ monarhiji in zunaj nje. Opogumljala sta jih panslavizem in srbski imperializem (Taylor 1948: 209, 228, 247; Stavrianos 2000: 461-66; Moll 2007: 212). Premik od severnih k južnim politično-gospodarskim navezam so v letih od 1917 do 1918 krepili različni mednarodni politični memorandumi in deklaracije, recimo Majska deklaracija (maja 1917), Krfska deklaracija (julija 1917), Wilsonovih štirinajst točk (januarja 1918) ter Ženevska deklaracija (oktobra 1918). Tako je bila 29. oktobra 1918 ustanovljena Država Slovencev, Hrvatov in Srbov (nekdanje Avstro-Ogrske), ki se je dober mesec pozneje združila s Kraljevino Srbijo v Kraljestvo Srbov, Hrvatov in Slovencev (1. decembra 1918). Vključevala je tudi ozemlje današnje Črne gore in Severne Makedonije.

Tako vedenje slovenske politične elite in njihovih podpornikov je bilo za Dunaj seveda »nepatriotsko « od samega začetka (Stavbar 2006; Moll 2007: 212), predstavljalo pa je še dodatno breme poleg 
drugih nacionalizmov (italijanskega, srbskega ipd.). Bilo je tudi ekonomsko nadležno, saj je bila od sredine devetnajstega stoletja prek Štajerske in Kranjske speljana strateško pomembna avstrijska južna železnica od Dunaja do Trsta (Taylor 1948: 203; Šnuderl 1988).

Kulturna arena obeh štajerskih $\gg$ zamišljenih skupnosti « (Anderson 1998) - nemške in slovenske - je vključevala šole, časopise, rituale / gledališče in vojsko (Hartman 2001; prim. Wallerstein 2006). Dodajmo še gospodarstvo (lastnina, davki, trgovina, finance in upravljanje; Baš 1988; Lešnik 1988; Šnuderl 1988; Hartman 1998; Pleterski 1998; Filipič 1991; Rozman 1991; Stavbar 2006). Prisotni so bili različni nacionalizmi: kulturni, ekonomski, pravni, verski, sorodstveni in drugi (prim. Eriksen 2010: 117-46).

Nemško prihodnost na Štajerskem sta podpirali dve veliki organizaciji. Od leta 1880 Nemško šolsko združenje (nemško Schulverein) $s$ sedežem v Berlinu, ki je še istega leta začelo delovati tudi v tedanji Avstriji. Druga sorodna organizacija je bila Južna marka (nemško Südmark), ustanovljena v Gradcu leta 1889, namenjena pa je bila krepitvi gospodarske moči in kolonizaciji nemškega prebivalstva, predvsem v zaledju Maribora proti Avstriji (Baš 1988: 23, 25, 28; Šnuderl 1988; Moll 2007: 210). Slovenska stran je tekmovala z lastno infrastrukturo: kulturnimi centri, časopisi, literaturo in knjižnicami, javnimi manifestacijami, obstrukcijami v deželnem in državnem zboru ter z odpiranjem slovenskih šol, kmetijskih zadrug in zadružnih bank, na primer z mariborsko Posojilnico. Ta posojilnica je leta 1918 odločilno podprla Maistrove vojaške operacije.

Rudolf Maister se je rodil v Kamniku na Kranjskem leta 1874. V času ustanovitve SLS (1892) je bil star osemnajst let. Tega leta se je odločil, da bo zapustil gimnazijo v Ljubljani in se raje vpisal na domobransko kadetnico na Dunaju, ki je nudila brezplačno šolanje in zaposlitev. Po šolanju je delal v enotah četrte veje avstrijske vojske, imenovane tudi »črna vojska « (Landsturm), namenjena pa je bila zaledni in civilni podpori. Do leta 1914 je dosegel čin stotnika. V času usposabljanja in napredovanja v vojaški hierarhiji je spoznaval topografijo in logistiko Kranjske, Koroške in Štajerske. Leta 1914 je začel služiti v vojaških skladiščih v Mariboru, 1916 pa je že postal začasni poveljnik okrožnega poveljstva »črne vojske« v Mariboru (Hartman 1998: 22).

Maister je sočasno pisal pesmi in slikal, $s$ čimer si je sčasoma prislužil naziva »vojak-pesnik « (Hartman 1998) in »vojak-slikar« (Ciglenečki 2011). Obiskoval je literarne krožke in jih podpiral, gostil ugledne intelektualce, objavljal pesmi in knjige ter sestavljal obsežno osebno knjižnico (danes ločen del domoznanskega oddelka Univerzitetne knjižnice Maribor). Poveljniki avstrijske vojske so ga 
zaradi njegovih dejanj in prepričanj nekajkrat kaznovali: na primer suspenz leta 1898 zaradi pretepa z nemškimi študenti v Celovcu ali pa premestitev v Galicijo leta 1908 in Gradec leta 1917 (Hartman 1998: 21-2, 25-6). Prav nasprotno pa je Maister s svojim kulturnim delovanjem pridobival zaupanje med slovenskimi intelektualci in politiki v Mariboru. Sčasoma je postal tesen sodelavec dr. Korošca, predsednika štajerske SLS. Slednji je leta 1917 prevzel tudi vodenje nacionalne SLS od dr. Ivana Šušteršiča, zagovornika slovenske avtonomije znotraj Avstrije. Obenem je Korošec takrat vodil Jugoslovanski klub $\mathrm{v}$ dunajskem parlamentu. Korošec in Maister sta bila idejna naslednika pokojnega Janeza Evangelista Kreka (1865-1917), zagovornika krščanskega socializma in pro-slovanske struje v SLS (glej Pleterski 1998: 39-42, 63-4).

Leta 1906 je Ariel Constantin Popovici, pravnik iz Transilvanije, podal predlog za možno skupno prihodnost avstro-ogrskih narodov: predlagal je Združene države Velike Avstrije (Vereinigte Staaten von Groß-Österreich) (Popovici 1906 v Case 2013). Cesar Franc Jožef I. je načrt predstavil leta $1910 \mathrm{v}$ enem od zadnjih poskusov, da bi rešil cesarstvo. Toda avstrijski parlament je federacijo zavrnil. Dvojna monarhija je bila za večino neučinkovita in neuravnotežena. Na Štajerskem so se davki povečevali vse od devetnajstega stoletja, najbolj zaradi širitve državne uprave in infrastrukture, šol in znanosti, socialnih politik, imperialnih naložb na Balkanu in podobno. Leta 1913 so se davki za gospodinjstva, podjetja in prevoz povečali za dodatnih petdeset odstotkov (Karner 2005: 41-2). Tributarno financiranje imperija ni bilo novo in je obenem definiralo vlogo južne marke v njegovem obrambnem sistemu (Pichler 1986; Pfeisinger 1996: 545; Kaser 2011: 52-6). Toda ob začetku prve svetovne vojne je tako financiranje postalo nesprejemljivo. Grožnja Osmanskega cesarstva za Kranjsko in Štajersko je dokončno izginila v balkanskih vojnah 1912-1913, kar je omogočilo »proti-imperialne vezi « med slovanskim prebivalstvom na Balkanu (Pleterski 1975; Stavrianos 2000: 413-24, 448-66) - in naredilo Dunaj manj samoumeven. Na Štajerskem pa je zaradi izseljevanja v ZDA in Nemčijo še naprej padalo število slovenskega prebivalstva (Moll 2007, citirano v Wörsdörferju 2007).

Čeprav so dunajski poslanci Popovicijev predlog zavrnili, je njegov zemljevid ponujal materialno in administrativno evidenco o etničnih zamejitvah v jugovzhodni Evropi (prim. Barth 1969; Gupta in Ferguson 1992). Med Združenimi državami Velike Avstrije se je takrat pojavila Kranjska (Krain) v skoraj natančni obliki današnje Slovenije. $\mathrm{Na}$ zemljevidu je od Maribora proti severu tekel tanek rdeč (etnični) koridor, ki je nemško mesto povezoval z nemško Avstrijo (Ude 1988). 
Štajerske perspektive Slovencev pred prvo svetovno vojno so bile precej drugačne od povojnih izidov. Kapitan Viktor Andrejka se je, recimo, julija in avgusta 1915 na neuradnem obisku v Ljubljani srečal z $\gg$ nekaterimi slovenskimi politiki«. Želel se je seznaniti z argumenti, ki bi spodbudili Slovence $\mathrm{k}$ sodelovanju v vojaškem spopadu z Italijo (od pomladi 1915). Njegove sogovornike je zanimala politična avtonomija znotraj avstrijske polovice dualistične države. V okviru tega so želeli polno avtonomijo za Kranjsko, kulturno avtonomijo Koroške ter kulturno-gospodarsko avtonomijo za Štajersko in Furlanijo. Njihov zamišljeni politični zemljevid slovenske države so sestavljale Kranjska, Istra in Gorica. Trst in Pulj naj bi ostajala avtonomna subjekta nemške Avstrije. Njihov program je bil »nekakšna velika Kranjska, ki se razteza na jug, brez Štajerske in Koroške « (Pleterski 1998: 339). Slovenski politiki niso vedeli za obljube, ki jih je antanta že dala Italiji v skrivni londonski pogodbi (aprila 1915) in so predvidevali, da bo Avstrija določala povojno prihodnost v tem delu Evrope. Maistrova misija tri leta pozneje se je zato soočila z imperialno kot tudi s kranjsko percepcijo Štajerske in Maribora.

\section{MAISTROV PREVRAT}

Vprašanju »prevrata « je bilo posvečenih res veliko zgodovinskih raziskav. Zgolj zaradi lažjega razumevanje razprave sledi nekaj golih mejnikov Maistrovega delovanja od oktobra 1918 do februarja 1919.

Maistrova vojaška intervencija »na terenu « se je začela s slovenskim nagovorom vojakom v mariborski vojašnici v Melju, dan po razglasitvi države Srbov, Hrvatov in Slovencev v Zagrebu (30. oktobra 1918; Hartman 1998: 38; Taylor 1948: 249). Maister je potem prevzel vojaško poveljstvo v Mariboru (1. novembra) (Hartman 1998: 41; Potočnik 2011) ter teden dni pozneje razglasil široko vojaško mobilizacijo na Štajerskem, Koroškem in Kranjskem (Hartman 1998: 53-6). Že 23. novembra je z enotami razorožil nemško mestno stražo in zavzel pošto, glavno informacijsko vozlišče tiste dobe (Hartman 1998: 59; Jenuš 2013: 226). Konec novembra 1918 so Maistrove enote napredovale proti severu, proti današnji avstrijski Koroški in Štajerski. Decembra so dobili še pomoč vojske Kraljestva Srbov, Hrvatov in Slovencev. Maister se je 2. januarja 1919 odločil, da bo zadržal dvaindvajset nemških talcev, da bi si s tem zagotovil poslušnost nemške manjšine $\mathrm{v}$ Mariboru. Njegovi stražniki so 27. januarja 1919 v splošni zmedi med stavkajočo množico pred Rotovžem ubili deset do petnajst ljudi. Od 
decembra 1918 do januarja 1919 so Maistrove enote spremljale namestitev lojalnega osebja v javne ustanove (Slavič 1928; Hartman 1998; Jenuš 2013). Slovenski jezik je postal uradni jezik Spodnje Štajerske.

\section{PODPORNI DEJAVNIKI}

Maistrove dosežke je mogoče popolnoma razumeti le $\mathrm{v}$ zvezi z različnimi predhodnimi in sočasnimi pogoji. Prvi pogoj je bil ideološki: nacionalni boji v avstro-ogrskem imperiju, ki so se okrepili v devetnajstem stoletju, ko so Slovani zavrnili premoč nemške kulture (Moll 2007: 207). Ob koncu prve svetovne vojne je postala slovenska ideja pomembna, drugače bi težko pojasnili velik odziv na Maistrovo mobilizacijo »slovenskih domoljubov«. Fizični boj Maistrovih vojakov je bil upravičen z ideologijo etnične politično-ekonomske emancipacije. Ko je prevzel poveljstvo avstrijske vojske v Mariboru (dva dni po razglasitvi države Srbov, Hrvatov in Slovencev v Zagrebu in dva dni pred uradno razpustitvijo avstrijske vojske) (Taylor 1948: 251; Hartman 1998: 33), ni imel ne mož ne zakonske pravice za kaj takega. Večina nižjih (nemških) častnikov v avstrijski vojski naj bi se sicer bolj malo zanimala za etnična vprašanja (Stergar 2004: 237).

Ob koncu prve svetovne vojne je bila nova meja na Štajerskem vpeta v razmerja moči v Evropi. Slovenci, Čehi, Hrvati in Romuni so bili ujeti v razmejitvene črte med rusko-srbskimi, nemško-avstrijski$\mathrm{mi}$, ameriško-britanskimi in francoskimi enotami in interesi. Avgusta 1919 sta Francija in Velika Britanija v St. Germainu nasprotovali referendumu na Spodnjem Štajerskem, vendar sta podprli tistega na Koroškem: njuni diplomati so ugotavljali, da v zadnjih devetih mesecih na Spodnjem Štajerskem pač ni bilo zaznati uradnega avstrijskega vojaškega odpora (Karner 2005: 130-31). Vlada na Dunaju je prosila Archibalda Caryja Coolidgeja - profesorja zgodovine in vodjo Posebne ameriške študijske skupine, ki je analizirala Srednjo Evropo in Balkan za potrebe ameriške udeležbe na pariški mirovni konferenci -, naj pošlje vojake na Spodnjo Štajersko. Odgovoril je, da Združene države ne morejo biti svetovni policist (Rahten 2011: 12, 14). Ameriški predsednik Wilson je bil morda »patetičen «, »slabo obveščen «, »počasen in neprilagodljiv « (Maynard Keynes, The Economic Consequences of the Peace, 1919 v Siracusa 2010: 38), toda za Slovence je bil Wilson osvoboditelj: »Ave Wilson! « V tem delu sveta se je ameriško stoletje začelo z odločitvijo, da podprejo Maistra. Ameriški vojaški svetovalec, polkovnik Sherman Miles, se ni javno odzval na streljanje v Mariboru 
med obiskom generala 27. januarja 1919 (Rahten 2011: 13-4). Osvoboditev slovanskih narodov je bila tudi v ruskem programu (Engels 1979; Jezernik 1998; Simonič 2009).

Pojdimo zdaj od geopolitičnih k vojaškim dejavnikom. Taylor je zapisal, da je bila Habsburška monarhija najmanj militarizirana država v tedanji Evropi. »V tridesetih letih po Berlinskem kongresu so se nemški izdatki za oborožitev povečali petkratno; angleški, ruski in francoski za trikrat; celo italijanski se je povečal za dvakrat in polkrat. Avstro-ogrska poraba se ni niti podvojila « (Taylor 1948: 229). Ne vem, ali je Maister poznal to statistiko, vendar je zelo dobro poznal strukturo in moč avstrijske vojske, saj je služil v različnih krajih Kranjske, Štajerske in Koroške. Nacionalizmi, mednarodni interesi in razpad front ob koncu vojne so Avstriji in Ogrski onemogočili, da bi obranili stare imperialne meje (Karner 2007: 130; Moll 2007; Šnuderl 1988: 81).

Slovenski Narodni svet za Štajersko (ustanovljen 26. septembra 1918), je že 28. septembra medse sprejel tudi Maistra. Oktobra so ga pooblastili, da z dr. Francem Kovačičem in Matijo Slavičem pripravijo podrobne karte etničnih meja na Štajerskem in Koroškem. Karte za Maistrove poznejše vojaške pozicije so bile pripravljene v nekaj tednih (Hartman 1998: 35, 38, 60). Narodni svet za Štajersko je 2. novembra 1918 povečal plačila Maistrovim prostovoljcem, da bi bila bolj privlačna in vsaj enakovredna plačilom mestne Zelene garde. Takrat so ustvarili dolg v mariborski Posojilnici, ki ga je ljubljanska vlada poplačala leta 1921 (Hartman 1998: 52). Dr. Karel Verstovšek, predsednik Narodnega sveta za Štajersko, je v prvih dneh novembra 1918 podpisal Maistrovo zahtevo, naj ga povišajo v naziv generala. Po Maistrovem mnenju je bilo to potrebno za kredibilnost v vojaških pogajanjih z višjimi častniki druge strani (Šnuderl 1988: 75; Hartman 1998: 51). Narodni svet - alternativni oblastni organ Slovencev - je bil vsekakor seznanjen in naklonjen Maistrovim stražnikom, njegovemu polku (ustanovljenemu 20. novembra 1918), teritorialnim zahtevam in diplomatskim prizadevanjem.

Naslednji pogoj Maistrove uspešnosti je bil prehranski. Avstrijsko jedro nekdanjega imperija je ob koncu vojne ostalo brez oskrbovalnih verig iz kmetijskega zaledja. Avstrijska diplomacija je morala paziti, da ne bi ogrozila dostave hrane sil antante (Karner 2005: 130-31). Deželna oblast v zgornještajerskem Gradcu se je odločila, da se bo izogibala vojaškim konfliktom na jugu: »Glavni razlog za to je bil, da bi Jugoslovani drugače odrezali Štajersko od močno potrebnih zalog hrane, ki so prihajale z juga « (Moll 2007: 213). V prvi polovici leta 1919 je Kraljestvo Srbov, Hrvatov in Slovencev Avstriji dostavilo od petindvajset do petinsedemdeset odstotkov različnih vrst hrane - kot 
nadomestilo za ugodnejšo razmejitveno črto (Karner 2005: 131). Skratka, avstrijska pozicija je bila ob koncu prve svetovne vojne slaba.

Hrana je bila najpomembnejša valuta $\mathrm{v}$ kaotičnih (liminalnih) mesecih od poletja 1918 do poletja 1919. Maister je že junija 1918, po več avstrijskih porazih na italijanski fronti pri reki Piavi, začel zadrževati zaloge $\mathrm{v}$ vojaških skladiščih in vagonih. Varovanje skladišč $\mathrm{v}$ vojaški hierarhiji ni bilo prestižno mesto, vendar se je Maistrovo poznavanje oskrbovalne in rezervne mreže avstrijske vojske izkazalo za strateško pomembno pri njegovih jesenskih akcijah in manevrih (glej Hartman 1998: 31, 38; Karner 2005: 130). Poleg tega je Kranjsko in Štajersko v novembru 1918 prečkalo več kot 400.000 razpuščenih vojakov, v decembru pa še 700.000, od tega 50.000 konjenikov, ki so se vračali z različnih front. Ljudje in mestne oblasti po državi so se bali ropanja in spopadov (Hartman 1998: 37-8, 48). V Mariboru so vojaške pekarne delale v povečanem obsegu cele tri tedne, občina pa je začasno zaposlila 130 žensk, da so množici razdeljevale hrano (Hartman 1998: 48-9). Maistru je 3. in 4 . novembra 1918 uspelo prepričati nekaj vojakov, ki so potovali skozi Maribor (Slovence, Srbe in druge), da so se pridružili njegovim enotam (Hartman 1998: 52-3). Nekateri so potem ostali z njim do demobilizacije (15. februarja 1919; Hartman 1998: 45) - tri tedne po pariški mirovni konferenci. Samo vojake, ki so se mu pridružili do sredine februarja 1919, so po letu 1933 sprejemali v Veteransko organizacijo borcev za severno mejo 1918-1919 (Penič 2011: 103). S hrano je Maister mogel pomiriti množico ob prvih dveh stavkah železničarjev in socialdemokratske stranke: 8. in 11. novembra 1918 (Hartman 1998: 49).

Maister je bil seveda uspešen tudi zaradi svojega osebnega talenta in volje. Narodni svet za Štajersko je iskal osebo, ki bi lahko nadzorovala vojašnice in enote v mestu. Hartman (1998) je Maistra predstavil kot fizično, duševno in verbalno močno osebo, pa tudi enega najbolj aktivnih članov Narodnega sveta. V habsburških vojaških dokumentih je bil opisan kot »visok, robusten, sila krepak, sicer pa čvrstega značaja, dobrodušen in miren « (Ciglenečki 2011: 160). Polkovnik Sherman Miles pa je po obisku pri Maistru konec januarja 1919 zapisal: »Perfekten primer vojaškega avanturista - močan, odločen, energičen, bister $\ll$ (Rahten 2011: 13-4).

\section{NEPOSREDNI ODZIVI}

Obrat slovenske politike od avstrijske k jugoslovanski zvezi leta 1917 je spremenil način presojanja in razmerja moči. Poleti 1917 ni bilo več 
nenavadno, da je predsednik SLS in Jugoslovanskega kluba na Dunaju dr. Korošec pri cesarju zahteval vrnitev Maistra s kazenske premestitve v Gradec nazaj na delovno mesto v Mariboru. V Gradcu si je takrat Maister celo prislužil čin majorja (Hartman 1998: 22, 30).

Dvojna igra dejstev in diplomacije med Ljubljano, Dunajem, Gradcem in Mariborom se je nadaljevala do leta 1919 in še naprej. Zanimivo je, da sta obe skupnosti - Nemci z Zgornje Štajerske in Maribora ter Slovenci iz Spodnje Štajerske in Maribora - menili, da njihovi osrednji vladi (Dunaj na eni in Ljubljana na drugi strani) v tistih $\gg$ odločilnih trenutkih « nista naredili dovolj (Karner 2005: 128-32; Moll 2007: 210-11; Šnuderl 1988: 78-9, 81). Obe nacionalni skupnosti oziroma njihovi voditelji so iskali podporo zunaj svoje domovine: Nemci v Nemčiji, Slovenci pa v jugoslovanstvu in Srbiji (Moll 2007, citirano v Wörsdörferju 2007).

Mariborski (nemški) mestni svet je 30. oktobra 1918 sprejel resolucijo, temelječo na Wilsonovi točki o pravici do samoodločbe, po kateri naj se Maribor, »staro nemško mesto «, pridruži nemški Avstriji (Hartman 1998: 36). Odzivi na Maistrova dejanja so se močno povečali v zadnjih dveh mesecih leta 1918, ko je prevzel vojaško poveljstvo v Mariboru, objavil mobilizacijo na Štajerskem, Kranjskem in Koroškem ter razorožil mariborsko mestno stražo. Avstrijska vlada je 15. novembra protestirala pri vladi v Ljubljani, da Maistrov mobilizacijski poziv nagovarja prebivalstvo na pravno še nedoločenih ozemljih (Hartman 1998: 53; Jenuš 2013: 226).

Narodna vlada v Ljubljani je prav tako nasprotovala vojaški samovolji Rudolfa Maistra (in Narodnega sveta). Z Dunajem se je pravkar pogajala o gospodarskih in političnih vprašanjih med Slovenijo in Štajersko (sporazum podpisan 7. novembra 1918, vendar neratificiran). Lovro Pogačnik, poveljnik za narodno obrambo pri Narodni vladi, je Maistrove operacije zavrnil kot »operete « (Hartman 1998: 53-6; Jenuš 2013: 226). Za nekatere spodnje-štajerske politike in zgodovinarje so bili taki odzivi vlade v Ljubljani znak njene »nesposobnosti, neupoštevanja, neumnosti, celo kaznivega ravnanja in malomarnosti«. Maister je prevzel vojaško poveljstvo v Mariboru in pri tem ni hotel poslušati ukazov iz Ljubljane, zaradi česar je postal tudi vzor za štajerski in mariborski patriotizem ter kolektivno karakterizacijo v novonastali državi po letu 1991.

Na Ženevski konferenci (6. - 9. novembra 1918) se je predsednik Korošec srečal s srbskim premierjem Nikolo Pašićem, ki mu je dal upanje za mirno rešitev ali pa vojaško pomoč Srbov (Šnuderl 1988: 78-9).

Poleg nesoglasij med slovenskimi voditelji s Kranjske in Spodnje Štajerske sta na presojanje Maistrovih dejanj vplivala tudi 
razredna in politična pripadnost opazovalcev. Mariborski socialni demokrati so se zdaj zavzemali za nemško Avstrijo. Skupaj z železniškimi delavci iz Maribora so organizirali tri stavke (8. novembra, 12. novembra in 27. januarja) (glej Baš 1988: 40; Šnuderl 1988: 75-9; Hartman 1998: 49; Jenuš 2913: 229-331). Na zadnji stavki je bilo ubitih več kot deset protestnikov, zato so nekateri mariborski Nemci med obema vojnama častili spomin na $\gg$ krvavi ponedeljek « in zanj krivili Maistrove orožnike (Švajncer 1988: 10; Promitzer 2012: 72; Ferlež 2012; Jenuš 2013: 230).

$\mathrm{Na}$ nekaterih obmejnih območjih med nemško Avstrijo in Kraljestvom Srbov, Hrvatov in Slovencev so se spopadi ponavljali do leta 1920. »Občutek varnosti se je vrnil na Zgornjo Štajersko šele leta 1921 «, piše Karner (2005: 136). Dodaja, da je bila nova meja »mrtva «, kar je bilo gotovo v nasprotju s preteklimi stoletji Vojvodine Štajerske. Neposredne posledice razmejitve so bile izguba naložb, zaprtje gospodarskih obratov in izseljevanje na obeh straneh meje. Etnični Nemci na Spodnjem Štajerskem in v Mariboru so dobili v jugoslovanski kraljevini drugačen status: statistični podatki v letih od 1921 do 1931 so zato zabeležili strm padec njihovega števila (Karner 2005: 135; Kosi in Cvirn 2012a, 2012b).

\section{MAISTER PO PRVI SVETOVNI VOJNI}

Že marca 1919 je Pihalni orkester Mariborskega polka izvedel uverturo Jugoslavija, » posvečeno prvemu slovenskemu generalu, Rudolfu Maistru «. Novembra 1919 so v Mariboru preimenovali Bismarckovo cesto (Bismarck Strasse) v Maistrovo ulico. Tam je Maister takrat tudi prebival (Hartman 1998: 124). Nov slovenski kult je tako nadomestil starega nemško-avstrijskega (Moll 2007, citirano na Wörsdörferju 2007).

Maistrov status in priljubljenost med vojaki in lokalnimi politiki nista zadržala nove centralne vlade v Beogradu v nameri, da ga že leta 1921 predčasno upokoji (Kocutar 2011: 112; Penič 2011). Po Hartmanovem mnenju (1998) je bila taka volja srbskega vodstva, ki ni zaupalo nekdanjemu avstro-ogrskemu osebju. Hkrati je prejel nagrado za svoj prispevek $\mathrm{k}$ nastanku nove države. $V$ tem pogledu je zanimivo, da je bil dr. Korošec sprejemljiv za »srbske unitariste « in je svojo kariero nadaljeval v visoki jugoslovanski politiki vse do smrti leta 1940 (Čepič 1991; Filipič 1991; Pleterski 1998). Zdi se, da sta bila vojaško priznanje Maistra na Štajerskem in konflikten odnos z nemško skupnostjo bolj problematična kot njegova prejšnja prisega drugi monarhiji. 
Decembra 1928, ob deseti obletnici prevrata, so Maistra izvolili za predsednika novega odbora Narodne odbrane. Njegov cilj je bil premagati gospodarsko stagnacijo in razdrobljenost slovenske politike (Hartman 1998: 114). Dr. Franjo Baš, etnolog, je pomagal odboru v razpravah o nemško-slovenskih odnosih na Štajerskem in v Kraljevini Srbov, Hrvatov in Slovencev (Maister in Šnuderl 1928; Baš 1928 v Hartman 1998: 114). Knjiga Slovenci v desetletju 1918-1928 (Mal 1928) je Maistra predstavila kot ključno osebo $v$ » političnem preobratu « pred desetimi leti (Slavič 1928).

Maister je kmalu postal tudi častni predsednik novoustanovljene organizacije veteranov borcev (Hartman 1998: 114). Od leta 1933 do 1998 je bila ta organizacija osrednji promotor Maistra, veteranov in domoljubja, predvsem na Štajerskem in le občasno na Kranjskem (Penič 2011).

Junija 1934 je Maister umrl v Uncu. Častnega pogreba v Mariboru se je udeležilo 25.000 ljudi (Hartman 1998: 118). Njegovim veteranom in privržencem so takrat dovolili odkriti bronasto portretno doprsje, avtorja Nika Pirnata, v mestni hiši (Rakovec 2015: 183-84).

Druga skupina Maistrovih vojakov je ustanovila ločeno veteransko organizacijo, imenovano Legija koroških borcev. Leta 1939 so načrtovali izdelavo spominske zbirke Maistrovih vojakov, vendar so v pričakovanju nemške okupacije »gradivo o slovenskih domoljubih « raje uničili (Švajncer 1988: 10).

\section{SPOMINI NA MAISTRA}

Med drugo svetovno vojno ni nobena uporniška enota nosila imena Rudolfa Maistra. Številni Maistrovi veterani so se pridružili partizanskemu odporniškemu gibanju, vendar vsi niso bili naklonjeni povojnemu socializmu.

Po drugi svetovni vojni je bila meja med Spodnjo in Zgornjo Štajersko (med Slovenijo in Avstrijo) najprej del evropske »železne zavese « med socialističnimi in kapitalističnimi državami. A dobro desetletje po ločitvi jugoslovanske in sovjetske politike, sta politično nevtralna Avstrija in neuvrščena Jugoslavija spodbujali mirne in odprte skupne meje. Gibanje delovne sile in blaga proti severu in blaga ter turistov proti jugu je bilo spet pogostejše, $\mathrm{k}$ temu pa so prispevale tudi regionalne pobude, kot je recimo Alpe-Adria. Jugoslavija je na ta način v 1960-ih in 1970-ih letih reševala gospodarsko krizo (Nećak 2001: 509-51), Avstrija pa naj bi si prizadevala premagati še izolacijo 
Zgornje Štajerske »v jugovzhodnem kotu svobodne Evrope « (Moll 2007: 216).

Makso Šnuderl (1988) in Bruno Hartman (1998) sta bila prepričana, da je bil sloves Rudolfa Maistra v socialističnih časih nezaželen zaradi njegove »meščanske provenience $\ll$. Z marksističnega stališča namreč sprememba oblasti leta 1918 ni bila revolucionarna, ker se je zamenjala le etnična pripadnost administracije, osnovni socialni in pravni pogoji delovanja družbe pa so ostali skoraj nedotaknjeni: ostala je ustavna monarhija (od Habsburžanov h Karađorđevićem) (Šnuderl 1988: 83). Janez Švajncer je še zapisal, da so mariborski socialisti podedovali predvojno socialdemokratsko stališče do Korošca in SLS, zato so Maistra preprosto odpisali kot enega od predstavnikov te konservativne, predrevolucionarne politike (Švajncer 1988: 10; prim. Filipič 1991).

Drugi razlog za izogibanje Maistru po drugi svetovni vojni naj bi bil njegov » kult osebnosti «: individualno junaštvo je bilo v nasprotju s kolektivistično mitologijo in vizijo socialistične države. Praznovanja in kipi so bili namesto tega namenjeni skupinam partizanov (operacije, brigade ali bataljoni) ali kvečjemu pomembnim revolucionarnim voditeljem (sic!) (Švajncer 1988: 10-1; Ciglenečki 2011). Maistrovih veteranov niso sprejemali v Zvezo borcev narodnoosvobodilne borbe iz druge svetovne vojne (Penič 2011: 104-5).

Jubilejnega leta 1948 tako ne zasledimo nobenih posebnih Maistrovih obeležij. Leta 1958 je Maistrovim veteranom uspelo postaviti spomenik borcem za severno mejo v središču Maribora. Na spomeniku je bil Maister na žalost nekaterih le eden od neizpostavljenih reliefov med kolegi borci (Hartman 1998: 47; Penič 2011: 102; Rakovec 2015: 192); od drugih nanizanih figur so ga ločevali le ponazorjeni brki, robovi oficirske uniforme in sablja. Istega leta so pripravili tudi obsežen spominski zbornik, vendar je »nekdo od zgoraj « interveniral pri Založbi Obzorja in preprečil tiskanje; vsaj tako pravi zgodba (Švajncer 1988: 10-1; Penič 2011: 102-3). Nekateri članki so bili zato natisnjeni šele deset ali trideset let pozneje (glej Švajncer idr. 1988). Leta 1971 so v Kamniku odkrili prvi Maistrov kip avtorja Antona Figulina (Hartman 1998: 40). Nekaj let pozneje, natančneje leta 1979, pa je izšel Spominski zbornik ob 60-letnici bojev za severno slovensko mejo 1918-1919z Maistrovimi besedili in spomini na prvo svetovno vojno (Kuster idr. 1979).

Konec 1980-ih let so socialistično jugoslovansko vsakdanjost pretresali gospodarska in politična kriza ter naraščajoči jugoslovanski nacionalizmi. Praznovanja, knjige in spomeniki, povezani z Rudolfom Maistrom, so imeli takrat na Spodnjem Štajerskem, še zlasti v Mariboru, 
patriotske konotacije. Trajni dosežek tega obdobja je bila postavitev prvega kipa Rudolfa Maistra avtorice Vlaste Zorko leta 1987 v Mariboru - na Leninovem trgu. Organizacija veteranov je izvedla obsežno akcijo zbiranja sredstev. Po njihovem prepričanju je bil to »prvi spomenik, ki so ga postavili po volji ljudi, ne pa vlade ali občine « (Rakovec 2015: 192-96). Kip je obrnjen proti jugu, domnevno zato, da ne bi povzročil nadaljnjih sporov z Avstrijo med še eno od koroških kriz. Sedemdeseto obletnico Maistrovega delovanja je zaznamoval tudi že omenjeni Švajncerjev zbornik Boj za Maribor 1918-1919.

Leta 1991 je Slovenija razglasila neodvisnost in ločitev od Jugoslavije. V zvezi s tem je dvajset let pozneje razpravljal slovenski vojaški zgodovinar Tomaž Kladnik. Po njegovem mnenju je bila Slovenska teritorialna obramba, ki se je leta 1991 borila proti Jugoslovanski armadi, v resnici »rezervna vojska drugega razreda « - podobna avstrijski formaciji Landsturma, $v$ kateri je deloval Maister. V obeh primerih so bile slovenske rezervne oborožene sile uspešne s podporo prebivalstva (Kladnik 2011: 67).

Razglasitev neodvisnosti Slovenije leta 1991 je prinesla bolj ali manj samoumeven družbeni obrat od jugoslovanstva in socializma (nazaj) k evropejstvu in kapitalizmu (Velikonja 2005). Slovenija in Avstrija (Spodnja in Zgornja Štajerska) sta znova postali članici iste nadnacionalne organizacije, tokrat Evropske unije. Schengensko območje je politično-ekonomsko mejo postavilo južno, proti Hrvaški. Meja med dvema Štajerskama se je zavestno in široko odprla trgovini, zaposlovanju, potovanju in različnemu čezmejnemu projektnemu sodelovanju.

$\mathrm{V}$ poosamosvojitvenem času se je Leninov trg v Mariboru preimenoval v Trg generala Maistra. Poleg Maistrovega kipa, ki je stal na njem, so že leta 1991 zasadili spominsko lipo neodvisnosti, kjer redno potekajo slovesnosti ob praznovanju dneva državnosti (Simonič 2009).

V Ljubljani so leta 1997 ustanovili Zvezo društev general Maister s ciljem, da bi mu že v naslednjem letu postavili kip v glavnem mestu. Ob dnevu državnosti leta 1999 so nasproti ljubljanske železniške postaje v Ljubljani odkrili veliki spomenik Maistra na konju (Žolnir in Piano 1999). Maister je obrnjen proti jugovzhodu. Drugo skulpturo Maistra na konju so postavili pred Ministrstvom za obrambo leta 2000 - bila je deležna še manjše pozornosti, čeprav sta to edina konjeniška spomenika v Sloveniji (Komić Marn 2013).

Celovita študija Bruna Hartmana Rudolf Maister, general in pesnik (1998) je obeležila sedemdeseto obletnico Maistrovega prevrata, meni pa je služila kot najpomembnejši biografski vir. Stara veteranska organizacija borcev za severno mejo se je sčasoma postarala in izgubila 
člane, zato so jo leta 1998 ukinili (Penič 2011). Od marca 2005 izročilo nadaljuje Domoljubno društvo generala Rudolfa Maistra.

Na praznovanju dneva državnosti leta 2005 so premierno odigrali Koračnico generala Maistra (avtorja Slavka Avsenika ml.). Istega leta je vlada Janeza Janše uporabila Maistra kot konstitutivni element državne teritorialne celovitosti. Uvedli so tri nove praznike: Dan združenja prekmurskih Slovencev z matičnim narodom (17. avgust), Praznik vrnitve Primorske k matični domovini (15. september) in Dan Rudolfa Maistra (23. november), ki obeležuje razorožitev Zelene garde leta 1918 (Taškar 2005: 2). Prvo nacionalno praznovanje generala Maistra v režiji Bojana Laboviča je jeseni 2005 potekalo v Štukljevi dvorani v Mariboru in ga je $\mathrm{v}$ živo prenašala slovenska nacionalna televizija.

Različna društva, poimenovana po Maistru, so leta 2007 ustanovila Nacionalno združenje general Rudolf Maister. Pred kratkim je združevalo petindvajset organizacij s približno 2.600 člani (Lovrenčič 2011: 139). Njihov cilj je » povezati potomce Maistrovih vojakov « ter »spodbujati patriotizem med mladimi in vojaki «.

Maister je sčasoma postal sestavni del slovenskega domoljubja ter celo evropske kulturne in politične dediščine. Uvrščen je bil med dvajset najpomembnejših tem $\mathrm{v}$ patriotskem izobraževanju $\mathrm{v}$ slovenskih osnovnih in srednjih šolah (Potočnik 2011). Z njegovo odločnostjo in domoljubjem se danes identificirajo tudi nekatere nacionalistične skupine kot so Kulturno društvo Črni Panter, Društvo za ohranjanje domoljubnih tradicij Hervardi, organizacija Blood and Honour (Kropej 2015) ali pa nazadnje ustanovljena Štajerska varda (P. J. 2018).

\section{HUMANISTIKA IN SIMBOLNI REDI}

Mit je zgodba, ki se je o določeni osebi, dogodku, prostoru ali pojavu oblikovala skozi čas in v sodobnosti deluje kot pomenski sklop ali identifikacijski kod. Miti opredeljujejo sorodstvene, teritorialne, interesne skupnosti, njihov izvor in drugačnost. Sodobni patriotski miti nastajajo, ko v jeziku nacionalne religije govorimo o mejah, o naravi, ko zgodovinski spomin predelujemo z umetnostmi, vpisujemo ljudi in dogodke $\mathrm{v}$ šolske in medijske programe ter izvajamo njim posvečene ceremonije in rituale - za dosego določenih ciljev v sodobnosti (Barth 2015 [1957]; Kertzer 1988; Čolović 2000; Weiner 2002; Simonič 2009; Jezernik 2013). Zato sem se v članku najprej posvetil zgodovinskemu kontekstu, potem Maistrovim neposrednim podpornikom in kritikom, nazadnje pa še izgradnji njegove podobe $\mathrm{v}$ 
pokrajinskem in nacionalnem spominu: $\mathrm{v}$ knjigah, spomenikih, praznikih in institucijah.

Slovenci so bili skozi dvajseto stoletje praviloma del nadnacionalnih političnih tvorb, prek katerih so presojali svet. Vpliv zunanjih dejavnikov je bil velik, še posebej zaradi maloštevilnosti in večinoma zemlji zavezanega ljudstva. Podobne značilnosti bi verjetno našli tudi v drugih majhnih državah, ki so po prvi svetovni vojni nastale na vzhodnih in južnih (kmečkih) obrobjih nekdanjega Habsburškega cesarstva.

Historiografsko gradivo za ta članek sem črpal iz treh glavnih univerzitetnih središč: Ljubljane, Maribora in Gradca, uporabil sem tudi drugo gradivo, da bi razširil spekter razprave. Slovensko nacionalno-patriotsko zgodovinopisje iz Ljubljane se je večinoma ukvarjalo s političnimi dogodki na Kranjskem: ta zgodovina je serija parlamentarnih razprav in boja za ideološko prevlado med Slovenci že od 1880-ih let. Politika je tu predvsem stvar kulture. Zgodovina slovenske politične emancipacije (državotvornosti) z mariborske strani je drugačna. Boj za slovensko prihodnost je bil v devetnajstem stoletju $\gg$ zapoznel « v primerjavi $s$ Kranjsko. V Mariboru je bila politična zgodovina dvajsetega in enaindvajsetega stoletja serija naglih in prisilnih prekinitev in je imanentno drugačna od tiste v Ljubljani. Maistrova dejanja so v kontekstu dominantne politične kulture opisana kot primer kulture tveganja (hazarda) in/ali primer nevsakdanjega poguma (prim. Guštin 2011).

Pisatelj Tone Partljič je recimo predlagal zanimiv zgodovinski profil Maribora. Po njegovem mnenju sta se nacionalno »junaštvo « in »prvinskost « mesta začela z Maistrom (1918), nadaljevala z napadom na dve nemški vozili v Volkmerjevem prehodu (1941), delavskimi stavkami (1988), spopadi slovenske teritorialne obrambe z jugoslovansko vojsko (1991) in »ljudsko vstajo « jeseni 2012. Slovenski »upori«v dvajsetem stoletju so se začenjali v Mariboru (Partljič 2012: 7).

V Mariboru in Ljubljani skorajda ni dvoma, da je bila slovenska pot Spodnje Štajerske pravična, smiselna in dolgoročno uspešna. Za avstrijsko zgodovinsko šolo pa je bila Maistrova delitev Štajerske dejanje izdajstva, ki sta ga spodbudila in omogočila panslavizem in vojna. Njegov uspeh je predstavljal neuspeh za razvoj nekoč enotne pokrajine (Moll 2007). Razlika med zgodovinarji je tudi v vzročnosti: medtem ko slovenski zgodovinarji slovenski nacionalizem razumejo kot odziv na naraščajočo grožnjo Nemčije (»germanizacije «), so avstrijski zgodovinarji pojasnili avstrijsko politiko kot odziv na povečan panslovanski pritisk z juga in vzhoda (»slovanizacijo «). V prostorskem smislu pa so slovenski zgodovinarji slovensko emancipacijo razumeli v luči etnične večine Slovencev v okoliških podeželskih skupnostih, medtem ko avstrijski avtorji poudarjajo nemški značaj mesta Marburg in 
njegove visoke kulture. To je dober primer spora dveh različnih vrst evropskih nacionalizmov: meščanskega in etničnega (glej Niedermüller 1994).

V razpravah o slovensko-nemških odnosih je leta 1928 Maistru pomagal slovenski etnolog Franjo Baš, kmalu nato prvi direktor Pokrajinskega muzeja Maribor. Njegovo ime se je pojavilo tudi pozneje, leta 1945, ko naj bi napisal poročilo Slovenski Nemci v razdobju 1918-1945 (Potočnik 1999). Zgodovinopisje, geografija, etnografija in statistika z obeh strani meje so sodelovali pri risanju razlik, meja in sožitja (Moll 2007: 213).

Najpogostejši povod za komemoracije in druge vrste poklonov Maistru so bila praznovanja, ki so potekala ob okroglih, desetih obletnicah. Sledeč naši analizi, so se glavni dosežki »maistrologije « zgodili okoli leta 1928, 1958, 1988 in 1998 ter seveda ob stoletnici prve svetovne vojne (glej Domovinsko društvo generala Rudolfa Maistra Maribor 2019). Od prve svetovne vojne Maister ni nikoli popolnoma izginil. Še posebej, kadar je slovenska ali štajerska družba doživljala prelome in prilagajanje novim mednarodnim okoliščinam, je bil priklican general: tako $\mathrm{v}$ desetletju pred drugo svetovno vojno, med razpadom Jugoslavije konec 1980-ih let kot tudi ob vzponu evropskih nacionalizmov v novem tisočletju.

Percepcija Maistra se je v zadnjih sto letih prilagodila številnim geopolitičnim okvirom, slovenska neodvisnost pa je odprla prostor za njegovo nacionalno kodificiranje. Konjenika v Ljubljani (1999, 2000) in Dan Rudolfa Maistra (2005) predstavljajo najvidnejše korake v procesu njegove nacionalizacije. Poleg uradnega vpisa ( $\mathrm{v}$ imenih šol, spomenikih, državnih odlikovanjih, praznikih ipd.) pa se Maister danes pojavlja tudi kot ikona nekaterih civilnodružbenih organizacij in blagovna znamka, recimo na pivu ali spominkih (Maistrovi čokoladni brki v Salonu uporabnih umetnosti v Mariboru).

\section{CITIRANE REFERENCE}

Anderson, Benedict 1998 Zamišljene skupnosti. Ljubljana: Studia Humanitatis.

BARTH, FREDRIK 1969 Ethnic Groups and Boundaries. Boston: Little Brown and Company.

Barthes, Roland 2015 Mitologije. Ljubljana: Krtina.

Bister, Feliks J. 1991 Življenje in delo Antona Korošca do prve svetovne vojne; Zdenko Čepič idr. ur. Življenje in delo dr. Antona Korošca; Prispevki za novejšo zgodovino, št. 1, str. 5-26. 
Case, Holly 2013 The Strange Politics of Federative Ideas in Eastern-Central Europe; The Journal of Modern History, št. 4, str. 833-866.

Ciglenečki, Marjeta 2011 Upodobitve Rudolfa Maistra; Časopis za zgodovino in narodopisje, št. 2-3, str. 156-179.

ČEPIČ, ZDENKo IDR. UR. 1991 Življenje in delo dr. Antona Korošca. Ljubljana: Inštitut za novejšo zgodovino (Prispevki za novejšo zgodovino).

Čolović, Ivan 2000 Politika simbola: ogledi o političkoj antropologijji. Beograd: Čigoja štampa.

Domovinsko Društvo generala Rudolfa Maistra Maribor 2019 Domovinsko društvo generala Rudolfa Maistra Maribor. https://www.facebook. com/Domovinsko-dru\%C5\%A1tvo-generala-Rudolfa-Maistra-Maribor-782877918448973/. Dostop: januar 2019.

Engels, Frederick 1979 Zunanja politika ruskega carizma; Marx in Engels, Dela, knj. 5, str. 525-577. Ljubljana: Cankarjeva založba.

Eriksen, Thomas Hylland 2010 Ethnicity and Nationalism. Anthropological Perspectives. London, New York: Pluto Press.

FerLeŽ, JeRneJA, UR. 2012 Nemci in Maribor: Stoletje preobratov 1846-1946. Maribor: Umetniški kabinet Primož Premzl.

FilipiČ, FranCE 1991 Dr. Anton Korošec in marksisti; Zdenko Čepič idr. ur. Življenje in delo dr. Antona Korošca; Prispevki za novejšo zgodovino, št. 1, str. 83-108.

Gellner, Ernest 1983 Nations and Nationalism. Oxford: Blackwell.

Gupta, Akhil, James Ferguson 1992 Beyond Culture: Space, Identity, and the Politics of Difference; Cultural Anthropology, št. 1, str. 6-23.

Guštin, Damijan 2011 Strateško-operativna (za)misel Rudolfa Maistra o uporabi oboroženih sil v času gradnje nacionalne države 1918-1919; Časopis za zgodovino in narodopisje, št. 2-3, str. 18-36.

HARTMAN, BRUno 1998 Rudolf Maister, general in pesnik. Ljubljana: DZS.

2001 Kultura v Mariboru. Maribor: Obzorja.

HAUC, Franci 1991 Spomenik resnice: Maribor dobil kip svojega prvega škofa Antona Martina Slomška; Slovenec, 30. septembra, str. 24.

Jenuš, Gregor 2013 »Es gibt einen Meister über alle irdische Maister «. Avstrijski odzivi na Maistrov prevzem oblasti v Mariboru in na Spodnjem Štajerskem v letih od 1918 do 1919; Arhivi, št. 2, str. 213-236.

JeZERNIK, BožIdAR 1998 Dežela, kjer je vse narobe: Prispevki k etnologiji Balkana. Ljubljana: Znanstveno in publicistično središče.

2008 »Svoji k svojim!« Politične in družbene dimenzije slovenskega narodnega vprašanja; Etnolog, št. 18 str. 65-74.

JeZERnik, BožIdar, UR. 2013 Heroji in slavne osebnosti na Slovenskem. Ljubljana: Znanstvena založba Filozofske fakultete (Zupaničeva knjižnica, 38).

KARNER, STEPHEN 2005 Die Steiermark im 20. Jahrhundert. Graz: Leykam. 
KASER, KARL 2011 Balkan und Naher Osten: Einführung in eine gemeinsame Geschichte. Wien: Böhlau Verlag.

Kertzer, David 1988 Ritual, Politics, and Power. New Haven, London: Yale University Press.

KLADNIK, Tomaž 2011 General Maister in oblikovanje slovenskih oboroženih sil v letih 1990-1991; Časopis za zgodovino in narodopisje, št. 2 -3, str. 67-85.

Kocutar, STANe 2011 General Rudolf Maister in njegovi soborci v mariborskem časopisju 1918-1934; Časopis za zgodovino in narodopisje, št. 2-3, str. 110-116.

Komić Marn, Renata 2013 Men on Horseback: The Role and Reception of the Equestrian Monument in Slovenia; Acta historiae artis Slovenica, št. 2, str. 57-114.

Kosi, JeRneJ, In JANeZ Cvirn 2012a Ukrepi proti nemški manjšini v letih 19191923; Jerneja Ferlež, ur. Nemci in Maribor: Stoletje preobratov 1846-1946, str. 68-69. Maribor: Umetniški kabinet Primož Premzl.

2012b Statistična asimilacija nemštva pri štetjih 1921 in 1931; Jerneja Ferlež, ur. Nemci in Maribor: Stoletje preobratov 1846-1946, str. 70-71. Maribor: Umetniški kabinet Primož Premzl.

KROPEJ, MONIKA 2015 Identifikacija slovenskih skrajnih nacionalističnih gibanj z Rudolfom Maistrom. Izpitna naloga pri predmetu Antropologija Balkana (neobjavljeno). Ljubljana: M. Kropej, Filozofska fakulteta, Oddelek za etnologijo in kulturno antropologijo.

LEŠNIK, MIRKo 1988 Dravska dolina pred prvo svetovno vojno; Janez Švajncer idr. ur. Boj za Maribor, str. 45-71. Maribor: Obzorja.

LOVRENČIČ, Milan 2011 Smoter ustanavljanja in delovanja društev generala Maistra; Časopis za zgodovino in narodopisje, št. 2-3, str. 136-142.

Maister, Rudolf, Makso Šnuderl 1928 Mi in naši Nemci. Maribor: Narodna odbrana.

KUSTER, JANKO IDR. UR. 1979 Spominski zbornik ob 60-letnici bojev za severno slovensko mejo 1918-1919. Maribor: Klub koroških Slovencev, Sklad Prežihovega Voranca; Ljubljana: Zveza prostovoljcev-borcev za severno slovensko mejo 1918-1919.

MAL, JosIP, UR. 1928 Slovenci $v$ desetletju 1918-1928. Zbornik razprav iz kulturne, gospodarske in politične zgodovine. Ljubljana: Leonova družba.

Moll, Martin 2007 The German-Slovene Language and State Border in Southern Austria: from Nationalist Quarrels to Friendly Co-Existence (19th to 21st Century); Steven G. Ellis, Lud'a Klusáková, ur. Imaging frontiers, contesting identities. Pisa: Pisa University Press.

NeĆAK, DušAn 2001 Die Alpen-Adria-Region 1945 bis 1991; Andreas Moritsch, ur. Alpen-Adria: Zur Geschichte einer Region. Klagenfurt: Hermagoras Verlag, Mohorjeva založba.

Niedermüller, Peter 1994 Politics, Culture and Social Symbolism: Some Remarks on the Anthropology of Eastern European Nationalism; Ethnologia Europaea, št. 1, str. 21-33. 
PANČUR, ANDREJ 2005 Začetek prve svetovne vojne; Jasna Fischer idr. ur. Slovenska novejša zgodovina 1848-1992, 1. knj. str. 123-125. Ljubljana: Mladinska knjiga.

PARTLJiČ, TONE 2012 Ljudje krize; Večer, 9. novembra, str. 7.

PENIČ, LoJZE 2011 Veteranska organizacija borcev za severno mejo 1918-1919; Časopis za zgodovino in narodopisje, št. 2-3, str. 99-109.

Pfeisinger, Gerhard 1996 Meje revolucije: Revolucija leta 1848 na Štajerskem, Slovenci in Dunajska oktobrska revolucija; Zgodovinski časopis, št. 4, str. 545-556.

Pichler, Franz 1986 Die steuerliche Belastung der steirischen Bevölkerung durch die Landesdefension gegen die Türken; Mittheilungen des steiermärkischen Landesarchives, št. 35-36: str. 71-104.

P. J. 2018 Nova obsodba Štajerske varde, tokrat od veteranov in domoljubov. Svet 24, 5. september. Internetni vir: https://novice.svet24.si/clanek/novice/ slovenija/5b8f9c96e0563/nova-obsodba-stajerske-varde-tokrat-od-veteranov-in-domoljubov. Dostop: januar 2019.

Pleterski, Janko 1975 Avstrija in Slovenci 1912-1913; Kronika, št. 2., str. 110-120.

1998 Dr. Ivan Šušteršič, 1863-1925. Pot prvaka slovenskega političnega katolicizma. Ljubljana: Znanstvenoraziskovalni center SAZU, Založba ZRC.

Potočnik, Dragan 1999 Mariborski Nemci v letih 1918-1941; Kronika, št. 1-2, str. 143-151.

2011 General Rudolf Maister in domoljubje pri pouku zgodovine; Časopis za zgodovino in narodopisje, št. 2-3, str. 143-155.

Promitzer, Christian 2012 Maribor kot mesto spomina avstrijskih Štajercev 19191941; Jerneja Ferlež, ur. Nemci in Maribor: Stoletje preobratov 1846-1946, str. 72-76. Maribor: Umetniški kabinet Primož Premzl.

RAHTEN, ANDREJ 2011 Mednarodne okoliščine Maistrove akcije; Časopis za zgodovino in narodopisje, št. 2-3, str. 5-17.

RAKovec, ANDREJA 2015 Komu so Mariborčani postavljali spomenike? Spomeniki znanih osebnosti v Mariboru; Maja Godina Golija, ur. Maribor in Mariborća$n i$, str. 181-202. Ljubljana: Založba ZRC SAZU.

SCOtT, Helen, UR. 2008 The Essential Rosa Luxemburg: Reform or Revolution \& General Strike. Chicago, Illinois: Haymarket books.

Simonič, Peter 2009 Kaj si bo narod mislil? Ritual slovenske državnosti. Ljubljana: Znanstvena založba Filozofske fakultete.

Siracusa, Joseph M. 2010 Diplomacy: A Very Short Introduction. Oxford: Oxford University Press.

SlaViČ, MATiJa 1928 Državni prevrat v mariborski oblasti; Josip Mal, ur. Slovenci v desetletju 1918-1928. Zbornik razprav iz kulturne, gospodarske in politične zgodovine, str. 215-270. Ljubljana: Leonova družba.

Stavbar, Vlasta 2006 Deklaracijsko gibanje 1917/18 na Spodnjem Štajerskem; $\check{C} a$ sopis za zgodovino in narodopisje, št. 2-3, str. 36-44.

Stavrianos, Leften Stavros 2000 The Balkans since 1453. London: Hurst \& Company. 
STERGAR, RoK 2004 Slovenci in vojska 1867-1914: Slovenski odnos do vojaških vprašanj od uvedbe dualizma do začetka 1. svetovne vojne. Ljubljana: Oddelek za zgodovino Filozofske fakultete (zbirka Historia).

ŠNUDERL, MAKSO 1988 Socialno politične osnove boja za Maribor in štajersko Podravje v letu 1918/19; Janez J. Švajncer idr. ur. Boj za Maribor, str. 72-83. Maribor: Obzorja.

ŠVAJNCER, JANEZ J. IDR. UR. 1988 Boj za Maribor. Maribor: Obzorja.

TAŠKAR, JANA 2005 Največjo veljavo ima kulturni praznik; Delo, 4. junija, str. 2.

TAYlor, Alan J. P. 1948 The Habsburg Monarchy 1809-1918. A history of the Austrian empire and the Austria-Hungary. London: Hamish Hamilton.

UdE, LoJZE 1988 Boj za Maribor in štajersko Podravje v letu 1918/19; Janez Švajncer idr. ur. Boj za Maribor, str. 84-128. Maribor: Obzorja.

Velikonja, Mitja 2005 Evroza: Kritika novega evrocentrizma. Ljubljana: Mirovni inštitut.

Weiner, JAmes 2002 Myth and mythology; Alan Barnard in Jonathan Spencer, ur. Encylopedia of Social and Cultural Anthropology, str. 583-587. London: Routledge.

WÖRSDÖRFER, Rolf 2007 Martin Moll: Kein Burgfrieden. Der deutschslowenische Nationalitätenkonflikt in der Steiermark 1900-1918 (recenzija); H-Soz-Kult, 3. septembra. Innsbruck: StudienVerlag.

ZveZa DRUŠTEV GENERAL MAISTER 2019 Zveza društev general Maister /http://zvezadgm.javno.si/ Dostop: januar 2019.

Žolnir, Nevenka in Brane Piano 1999 V Ljubljani so postavili spomenik generalu Maistru; Delo, 26. junija, str. 1. 